\title{
HUBUNGAN KARAKTERISTIK DENGAN PENGETAHUAN TOKOH MASYARAKAT MENGENAI KEBERADAAN POSYANDU DI WILAYAH KERJA PUSKESMAS JATINANGOR
}

\author{
Didah*) \\ 1'Departemen IImu Kesehatan Masyarakat Fakultas Kedokteran Universitas Padjadjaran. \\ Email : didahramdani@gmail.com
}

\begin{abstract}
Background: Posyandu (Integrated Health Post) was one of the government's health programs by empowering communities to realize optimal community health degrees. Posyandu was located in a community environment. There were community leaders in a society. Community leaders were the driving element in mobilizing the community to play an active role in the activities of the posyandu.

Purpose: Knowledge was the factor that influenced community leaders on the existence of posyandu in the community. Knowledge could be influenced by age, education and employment.

Methods: This study used a cross-sectional study. The research sample was the leader of neighbourhood and hamlet in the work area of the Jatinangor Health Center. Sampling used proportional stratified random sampling technique with the number sample was 78 respondents. Data analysis used Gamma Test.

Results: Showed that the majority of respondents were aged 20-49 years, worker and last education from high school. The characteristic and knowledge was associated. This was shown by $p$ value $<0.05$.

Conclusion: Based on the results of this study it could be concluded that there was a relationship between the characteristics and knowledge of community leaders on the existence of posyandu.

Keywords: Characteristics, Knowledge, Posyandu, Community Leaders
\end{abstract}

\section{ABSTRAK}

Latar Belakang: Posyandu merupakan salah satu program kesehatan pemerintah dengan memberdayakan masyarakat agar dapat mewujudkan derajat kesehatan masyarakat yang optimal. Posyandu berada dilingkungan masyarakat, di lingkungan masyarakat terdapat orang yang ditokohkan yang disebut dengan tokoh masyarakat. Tokoh masyarakat merupakan unsur penggerak dalam menggerakan masyarakat agar berperan aktif dalam kegiatan posyandu.

Tujuan: Pengaruh tokoh masyarakat terhadap keberadaan posyandu di lingkungan masyarakat dipengaruhi oleh pengetahuan. Faktor yang memengaruhi pengetahuan adalah usia, pendidikan, dan pekerjaan.

Metode: Pendekatan cross-sectional. Sampel penelitian ini adalah bagian dari Tokoh Masyarakat yaitu RT dan RW di wilayah kerja Puskesmas Jatinangor. Pengambilan sampel menggunakan teknik proportional stratified random sampling dengan jumlah sampel 78 responden. Analisis data menggunakan Uji Gamma.

Hasil: Responden terbanyak berusia 20-49 tahun, bekerja dan berpendidikan terakhir SMA. Responden paling banyak memiliki pengetahuan cukup 49 responden $(62,8 \%)$. Hubungan karakteristik tokoh masyarakat dengan pengetahuan tokoh masyarakat terhadap keberadaan posyandu bernilai $p<0,05$.

Simpulan: Terdapat hubungan antara karakteristik dengan pengetahuan tokoh masyarakat terhadap keberadaan posyandu.

Kata Kunci: Karakteristik, Pengetahuan, Posyandu, Tokoh Masyarakat

\section{PENDAHULUAN}

Posyandu merupakan salah satu program kesehatan pemerintah dengan memberdayakan masyarakat agar dapat mewujudkan derajat kesehatan masyarakat yang optimal (Kemenkes RI, 2012). Posyandu berada dilingkungan masyarakat, agar masyarakat dapat mengelola dan memperoleh pelayanan kesehatan dasar dalam kegiatan posyandu. Dengan adanya posyandu maka masyarakat dapat berperan nyata dalam meningkatkan kesehatan mereka sendiri, masyarakat dapat dengan mudah memantau dan 
medeteksi kesehatannya. Keberadaan posyandu dapat memberikan manfaat bagi masyarakat dalam meningkatkan kesejahteraan kesehatan dengan meningkatkan harapan hidup masyarakat.

Posyandu berada dilingkungan masyarakat, di lingkungan masyarakat terdapat orang yang ditokohkan yang disebut dengan tokoh masyarakat. Tokoh masyarakat merupakan unsur penggerak dalam menggerakan masyarakat agar berperan aktif dalam kegiatan posyandu. Pengaruh tokoh masyarakat terhadap keberadaan posyandu di lingkungan masyarakat dipengaruhi oleh pengetahuan, dalam menjamin keberhasilan posyandu tidak hanya merupakan tugas kader dan petugas kesehatan, tetapi tokoh masyarakat juga berperan dalam hal itu. Tokoh masyarakat berperan dalam memotivasi masyarakat untuk datang ke posyandu. Sehingga tokoh masyarakat sangat berpengaruh dan ditokohkan oleh masayarakat di lingkungannya (kemenkes RI, 2011).

Pengetahuan merupakan informasi yang dimiliki oleh seseorang terhadap suatu hal. Pengetahuan merupakan hasil dari tahu yang terjadi melalui proses sensoris panca indera khususnya mata dan telinga terhadap objek tertentu). Pengetahuan tokoh masyarakat mengenai posyandu merupakan informasi yang dimiliki tokoh masyarakat mengenai posyandu dan manfaatnya di lingkungan masyarakat. Faktor yang memengaruhi pengetahuan adalah tingkat pendidikan, usia, dan pekerjaan. Pengetahuan tokoh masyarakat mengenai posyandu merupakan informasi yang dimiliki tokoh masyarakat mengenai posyandu dan manfaatnya di lingkungan masayarakat (Wawan, 2010).

Tingkat pendidikan mempengaruhi kualitas pengetahuan seseorang. Semakin tinggi tingkat pendidikan akan berbanding lurus dengan pengetahuannya. Selain mempengaruhi pengetahuan, pendidikan pun berpengaruh terhadap minat seseorang. Semakin tinggi tingkat pendidikan seseorang maka minatnya dalam berperilaku mendukung keberadaan posyandu di lingkungannya semakin tinggi (Mubarak, 2011).

Selain itu, faktor lain yang mempengaruhi pengetahuan adalah umur serta pekerjaan. Dengan bertambahnya umur seseorang, akan terjadi perubahan aspek fisik dan mental yang akan berpengaruh pada responnya terhadap suatu hal. Semakin bertambah umur tokoh masyarakat, maka pengetahuan yang dimilikinya akan bertambah, karena pengetahuan dapat diperoleh dari pengalaman yang dimiliki seseorang. Pekerjaan juga merupakan salah satu faktor yang mempengaruhi pengetahuan. Seseorang yang bekerja akan mendapat informasi dan pengalaman yang lebih banyak sehingga berpengaruh kepada tingkat pengetahuan yang dimilikinya (wijaya, 2014).

Tingkat pengetahuan dalam kategori rendah yang dimiliki oleh TOMA akan memengaruhi partisipasinya dalam memberdayakan masyarakat untuk kegiatan posyandu, karena pengetahuan merupakan predisposing factor atau faktor yang mempermudah perubahan sikap seseorang (Darmwan, 2015). Pengetahuan mengenai posyandu dapat memengaruhi sikap penerimaan tokoh masyarakat terhadap keberadaan posyandu, sehingga tokoh masyarakat berkewajiban untuk meningkatkan pemahamannya tentang posyandu. Maka dari itu, salah satu hal dapat dilakukan oleh tenaga kesehatan adalah memberikan promosi kesehatan atau penyuluhan yang dapat meningkatkan pengetahuan tokoh masyarakat, sehingga pada akhirnya muncul kesadaran untuk melakukan perilaku hal yang mendukung terhadap keberadaan posyandu dengan mengajak masyarakat untuk berpartisipasi dalam kegiatan posyandu (Tumbelaka Patricia, dkk, 2018).

\section{METODOLOGI PENELITIAN}

Penelitian ini dilakukan dengan metode analitik menggunakan pendekatan potong lintang (cross sectional). Populasi dalam penelitian ini adalah tokoh masyarakat yang berada di wilayah Puskesmas Jatinangor. Sampel dalam penelitian ini diambil dengan teknik proportionate stratified random sampling dan simple random sampling. Proportionate stratified random sampling adalah teknik pengambilan sampel dengan menetapkan jumlah populasi pada tiap kelompok atau strata. Sehingga, besar sampel tokoh masyarakatnya adalah 78 orang. Sumber data yang digunakan adalah data primer yang diperoleh dari hasil pengisian kuesioner. Analisis data menggunakan Uji Korelasi Gamma.

\section{HASIL DAN PEMBAHASAN}

Penelitian ini terdiri dari 78 responden untuk mengetahui hubungan pengetahuan, sikap dan perilaku tokoh masyarakat dengan strata posyandu sesuai dengan desanya. Hasil penelitian tersebut dapat dilihat dari tabel dibawah.

Dalam penelitian dibawah didapatkan lebih banyak responden yang bekerja yaitu sebanyak 50 responden $(64,1 \%)$, responden paling banyak berpendidikan SMA yaitu 29 responden $(37,2 \%)$ tetapi masih terdapat 16 responden $(20,5 \%)$ yang berpendidikan SD. 
Tabel 1 Distribusi Frekuensi Karakteristik Responden

\begin{tabular}{ccc}
\hline Karakteristik Responden & N & $\%$ \\
\hline Kelompok Usia & 49 & \\
$20-49$ tahun & 26 & 32,8 \\
$50-64$ tahun & 3 & 3,3 \\
$>64$ tahun & & \\
Pekerjaan & 31 & 39,7 \\
Wiraswasta & 2 & 2,6 \\
Pegawai Swasta & 2 & 2,6 \\
Guru & 28 & 35,9 \\
Ibu Rumah Tangga & 7 & 9,0 \\
PNS & 8 & 10,2 \\
Buruh & 16 & \\
Pendidikan Terakhir & 25 & 20,5 \\
SD & 29 & 32,1 \\
SMP & 4 & 37,2 \\
SMA & 4 & 5,1 \\
D3 & 78 & 100 \\
S1 & &
\end{tabular}

Tabel 2

Hubungan Karakteristik dengan Tingkat Pengetahuan Tokoh Masyarakat mengenai Posyandu

\begin{tabular}{|c|c|c|c|c|c|c|c|c|c|}
\hline \multirow{3}{*}{$\begin{array}{l}\text { Karakteristik Tokoh } \\
\text { Masyarakat }\end{array}$} & \multicolumn{8}{|c|}{ Pengetahuan Tokoh Masyarakat } & \multirow{3}{*}{ Nilai $p$} \\
\hline & \multicolumn{2}{|c|}{ Baik } & \multicolumn{2}{|c|}{ Cukup } & \multicolumn{2}{|c|}{ Kurang } & \multicolumn{2}{|c|}{ Total } & \\
\hline & $\mathrm{N}$ & $\%$ & $\mathrm{~N}$ & $\%$ & $\mathrm{~N}$ & $\%$ & $\mathrm{~N}$ & $\%$ & \\
\hline \multicolumn{10}{|l|}{ Kelompok Usia } \\
\hline $20-49$ tahun & 12 & 24,5 & 31 & 63,3 & 6 & 12,2 & 49 & 100 & \multirow{3}{*}{0,034} \\
\hline $50-64$ tahun & 10 & 38,5 & 15 & 57,7 & 1 & 3,8 & 26 & 100 & \\
\hline$>64$ tahun & 0 & 0 & 3 & 100 & 0 & 0 & 3 & 100 & \\
\hline Total & 22 & 28,2 & 49 & 62,8 & 7 & 9,0 & 78 & 100 & \\
\hline \multicolumn{10}{|l|}{ Pekerjaan } \\
\hline Wiraswasta & 5 & 16,1 & 24 & 77,4 & 2 & 6,5 & 31 & 100 & \multirow{6}{*}{0,046} \\
\hline Pegawai Swasta & 1 & 50,0 & 1 & 50,0 & 0 & 0 & 2 & 100 & \\
\hline Guru & 2 & 100 & 0 & 0 & 0 & 0 & 2 & 100 & \\
\hline Ibu Rumah Tangga & 8 & 28,6 & 16 & 57,1 & 4 & 14,3 & 28 & 100 & \\
\hline PNS & 4 & 57,2 & 3 & 42,8 & 0 & 0 & 7 & 100 & \\
\hline Buruh & 2 & 25,0 & 5 & 62,5 & 1 & 12,5 & 8 & 100 & \\
\hline Total & 22 & 28,2 & 49 & 62,8 & 7 & 9,0 & 78 & 100 & \\
\hline \multicolumn{10}{|l|}{ Pendidikan Terakhir } \\
\hline SD & 2 & 12,5 & 10 & 62,5 & 4 & 25 & 16 & 100 & \multirow{5}{*}{0,037} \\
\hline SMP & 3 & 12,0 & 19 & 76,0 & 3 & 12,0 & 25 & 100 & \\
\hline SMA & 14 & 48,3 & 15 & 51,7 & 0 & 0 & 29 & 100 & \\
\hline D3 & 1 & 25,0 & 3 & 75,0 & 0 & 0 & 4 & 100 & \\
\hline $\mathrm{S} 1$ & 2 & 50,0 & 2 & 50,0 & 0 & 0 & 4 & 100 & \\
\hline Total & 22 & 28,2 & 49 & 62,8 & 7 & 9,0 & 78 & 100 & \\
\hline
\end{tabular}

Berdasarkan tabel di atas, didapatkan hasil bahwa hubungan karakteristik umur tokoh masyarakat dengan pengetahuan mengenai posyandu memiliki nilai $p \quad 0,034$, hubungan karakteristik pekerjaan tokoh masyarakat dengan pengetahuan mengenai posyandu memiliki nilai $p$ 0,046, dan hubungan karakteristik tingkat 
pendidikan tokoh masyarakat dengan pengetahuan mengenai posyandu memiliki nilai $p 0,037$.

Responden yang memiliki tingkat pengetahuan baik paling banyak berada pada kelompok usia 20-49 tahun yaitu 12 responden (24,5\%), 14 responden $(63,6 \%)$ dari 22 responden yang memiliki pengetahuan baik yaitu bekerja, dan 14 responden $(63,6 \%)$ dari 22 responden yang memiliki pengetahuan baik berpendidikan terakhir SMA.

Hasil analisis data dengan menggunakan $\mathrm{Uji}$ korelasi Gamma menunjukan $p$ value $<0,05$ sehingga disimpulkan bahwa terdapat hubungan yang signifikan antara Karakteristik umur, tingkat pendidikan dan pekerjaan tokoh masyarakat dengan pengetahuan tokoh masyarakat mengenai posyandu.

Hasil penelitian menunjukan bahwa sebagian responden memiliki tingkat pengetahuan yang cukup dan baik mengenai posyandu. 22 $(28,2 \%)$ dari 78 responden memiliki tingkat pengetahuan yang baik dan $49(62,8 \%)$ responden memiliki pengetahuan yang cukup. Pengetahuan yang cukup dan baik dapat diperoleh dari berbagai sumber, diantaranya seperti media massa (cetak dan elektronik), buku-buku, serta informasi yang didapat dari petugas kesehatan.

Tokoh masyarakat merupakan salah satu pihak yang dapat memengaruhi keberadaan posyandu. selain tokoh masyarakat terdapat juga kader yang merupakan pihak yang dapat memengaruhi keberadaan posyandu. Tokoh masyarakat dan kader berada langsung $\mathrm{di}$ lingkungan masyarakat, sehingga kedua pihak ini dapat bekerjasama dalam mengelola posyandu. Menurut Makhfudli (2009) bahwa kader merupakan bagian dari tokoh masyarakat apabila kader tersebut ditokohkan di lingkungan masyarakat, dan karena kader berada langsung di lingkungan masyarakat.

Dalam penelitian ini responden yang merupakan tokoh masyarakat, ada beberapa tokoh masyarakat yang juga menjadi kader. Pada saat ini masih sedikit yang melakukan penelitian kepada tokoh masyarakat mengenai posyandu, sehingga menjadi keterbatasan peneliti dalam melakukan pembahasan mengenai hasil penelitian ini dengan penelitian sebelumnya. Pada pembahasan penelitian ini, peneliti membahas penelitian sebelumnya mengenai kader, karena kader dan tokoh masyarakat berada langsung di lingkungan masyarakat dan peran tokoh masyarakat dan kader berbanding lurus dalam keberadaan posyandu.

Menurut Notoatmodjo (2010) bahwa kurangnya informasi menjadi salah satu faktor yang memengaruhi rendahnya pengetahuan. Sumber informasi kesehatan dapat diperoleh dari tenaga kesehatan, kader maupun media massa. Dalam penelitian ini terdapat $9,0 \%$ atau 7 responden yang memilki pengetahuan yang kurang. Sebagian besar responden dalam penelitian ini mengatakan belum pernah mengikuti pelatihan untuk memperoleh informasi mengenai posyandu. Menurut Mubarak (2011) bahwa tingkat pendidikan memengaruhi kualitas pengetahuan seseorang, semakin tinggi tingkat pendidikan akan berbanding lurus dengan pengetahuannya. ${ }^{8}$ Pernyataan tersebut sesuai dengan hasil penelitian ini bahwa banyaknya tingkat pengetahuan responden yang cukup dipengaruhi oleh tingkat pendidikan responden terbanyak yaitu tingkat SMA. Tingkat pendidikan seseorang akan mempermudah proses penerimaan informasi dan nilai-nilai baru, tetapi belum tentu mempengaruhi tingkat pengetahuan karena pengetahuan dapat dipengaruhi oleh faktor lainnya seperti intelegensia, minat, umur, dan pekerjaan.

Hasil penelitian menunjukan bahwa terdapat $28,2 \%$ responden yang memiliki pengetahuan baik. Dua belas dari 22 responden yang memiliki pengetahuan baik berusia 20-49 tahun. Usia merupakan salah satu faktor yang memengaruhi pengetahuan. Semakin bertambahnya usia seseorang maka akan terjadi peningkatan daya tangkap serta pola berpikir sehingga pengetahuan yang diperolehnya semakin baik. Tetapi hasil penelitian ini tidak sesuai dengan teori usia menurut Notoatmodjo. Hasil penelitian sesuai dengan Mubarak (2011) bahwa pengetahuan dipengaruhi oleh minat keingintahuan seseorang terhadap suatu hal, dan minat seseorang terhadap suatu hal akan meningkat pada saat usianya masih produktif.

Terdapat $9.0 \%$ responden yang memiliki pengetahuan yang kurang. Dari hasil penelitian tampak 4 dari 7 responden yang memiliki pengetahuan kurang tidak bekerja. Bekerja merupakan salah satu faktor yang dapat memudahkan seseorang memperoleh pengalaman dan pengetahuan baik secara langsung maupun tidak langsung. Faktor lain yang menyebabkan kurangnya pengetahuan adalah kurangnya informasi yang diperoleh responden. Kurangnya informasi yang diperoleh mempengaruhi tingkat pengetahuan yang dimiliki oleh responden. Seseorang yang memiliki sumber informasi yang lebih banyak akan memiliki pengetahuan yang lebih luas pula.

Pengetahuan yang dipengaruhi oleh usia, tingkat pendidikan dan pekerjaan akan memengaruhi perilaku berupa dukungan tokoh mayarakat dalam keberlangsungan posyandu 
dengan memberikan motivasi kepada masyarakat untuk datang ke posyandu. Berdasarkan penelitian Nazri Cut (2016) bahwa faktor yang memengaruhi partisipasi masyarakat atau ibu yang memiliki balita untuk datang ke posyandu adalah berupa motivasi dan dorongan dari beberapa pihak, salah satunya adalah tenaga kesehatan berupa pemberian informasi mengenai pentingnya posyandu, dan kerjasama kader serta tokoh masyarakat dalam mengajak masyarakat untuk datang berpartisipasi dalam kegiatan posyandu secara rutin. Penelitian tersebut sesuai dengan hasil peneliat Halwandi (2013) bahwa salah satu faktor yang memengaruhi partisipasi masyarakat dalam kegiatan posyandu adalah adanya dukungan dari berbagai pihak salah satunya adalah tokoh masyarakat dan kader dalam mengajak masyarakatnya untuk dtaang ke posyandu dan memberitahu mengenai jadwal hari posyandu.

Berdasarkan hasil penelitian dapat disimpulkan bahwa terdapat hubungan yang bermakna antara pengetahuan, sikap, dan periaku tokoh masyarakat dengan keberadaan posyandu.

Saran untuk penelitian ini adalah Puskesmas disarankan agar memberikan informasi mengenai keberadaan posyandu dan menyelenggarakan pelatihan mengenai peran tokoh masyarakat terhadap posyandu agar dapat meningkatkan pengetahuan dan kesadaran tokoh masyarakat mengenai perannya terhadap posyandu.

\section{SIMPULAN}

Terdapat hubungan antara karakteristik TOMA dengan tingkat pengetahuan mengenai keberadaan posyandu.

\section{SARAN}

Berdasarkan hasil penelitian, diharapkan TOMA berperan aktif lagi dalam kegiatan posyandu, karena peran TOMA seperti RT dan RW sangat berpengaruh dalam pelaksanaan kegiatan posyandu.

\section{DAFTAR PUSTAKA}

Akbar Abdillah, Gani Husni Abdul, Istiaji Edi. Dukungan Tokoh masyarakat dalam Keberlangsungan Desa Siaga di Desa Kenogo Kecamatan Gucialit Kabupaten Lumajang ejournal Pustaka Kesehatan. 2015;3(3):522-29.

Budiman, Riyanto A. Kapita Selekta Kuesioner Pengetahuan dan Sikap dalam Penelitian Kesehatan. Jakarta: Salemba Medika; 2013.
Darmawan Kompiang Ngurah. Faktor-faktor yang memengaruhi Perilaku Kunjungan Masyarakat terhadap Pemanfaatan Pelayanan Posyandu di Desa Pemecutan Kelod Kecamatan Denpasar Barat. Jurnal Dunia Kesehatan. 2015;5:29-39.

Bahtiar Yanyan. Hubungan Pengetahuan dan Sikap Tokoh Masyarakat dengan Perannya dalam Pengendalian Demam Berdarah di Wilayah Puskesmas Kawalu Kota Tasikmalaya. Aspirator. 2012;4:73-84.

Gondowardojo Y, Wirakusuma I. Tingkat Pengetahuan, Sikap, dan Perilaku lbu Mengenai Pemberian Imunisasi Dasar pada Bayi di Wilayah Kerja Puskesmas Bebandem Tahun 2014. 2014:10.

Halwandi, Siziya, Magnussen, Olsen. Factor Perceived by Caretakers as Barries to Health Care for Under-Five Children in Mazabuka District, Zambia. ISRN Trop Med. 2013;10.

Kementerian Kesehatan Republik Indonesia. Ayo ke Posyandu Setiap Bulan. Jakarta: Kementerian Kesehatan Rl; 2012.

Kementerian Kesehatan Republik Indonesia. Pedoman Umum Pengelolaan Posyandu. Jakarta: Kementerian Kesehatan Rl; 2011.

Lestari S. Hubungan Tingkat Pendidikan, Pengetahuan, dan Sikap lbu Rumah Tangga dengan Perilaku Deteksi Dini Kanker Serviks Metode IVA di Puskesmas Jaten II Kabupaten Karanganyar. Surakarta: Universitas Sebelas Maret; 2013.

Makhfudli. Efendi Ferry. Keperawatan Kesehatan Komunitas. Jakarta: Salemba Medika; 2009.

Maternity Dainty, Putri Ratna Dewi, Aulia Devy Lestari Nurul. Asuhan Kebidanan Komunitas. Yogyakarta: Penerbit ANDI; 2017.

Mubarak. Promosi Kesehatan untuk Kebidanan. Jakarta: Salemba Medika; 2011.

Nazri Cut, Yamazaki Chico, Kameo Satomi, Herawati Dewi, Sekarwana Nanan, Raksanagara Ardini, et al. Factors Influencing Mother's Participation in Posyandu for Improving Nutritional Status of Children Under-Five in Aceh Utara District, Aceh Province, Indonesia BMC Public Health. 2016;16:69:1-9.

Notoatmodjo S. IImu Perilaku Kesehatan. Jakarta: PT RINEKA CIPTA; 2010.

Noerjoedianto Dwi, Amir Andy, Herwansyah Nurhusna. Penguatan Kader Posyandu 
dalam Upaya Deteksi Dini Kesehatan Ibu, Bayi, dan Balita di Wilayah Kecamatan Telanaipura Kota Jambi Tahun 2013. Pengabdian pada Masyarakat. 2014;29:4353.

Notoatmodjo S. Promosi Kesehatan Teori dan Aplikasi Jakarta: Rineka Cipta; 2010.

Riza A, Atoillah M. Faktor yang Berhubungan dengan Peran Aktif Kader dalam Penjaringan Kasus Probable Difteri. Jurnal Berkala Epidemiologi. 2015;3:353-65.

Sihombing Kanda, Kandarina Istiti, Sumarni. Peran Lurah, Petugas Kesehatan, dan Kader dalam Partisipasi lbu Balita ke Posyandu di Wilayah Cakupan D/S Terendah dan Tertinggi di Kota Jambi. Jurnal Gizi dan Dietetik Indonesia. 2015;3(2):87-97.

Sulaeman Endang Sutisna, Murti Bhisma, Waryana. Peran Kepemimpinan, Modal Sosial, Akses Informasi serta Petugas dan Fasilitator Kesehatan dalam Pemberdayaan
Masyarakat Bidang Kesehatan. Jurnal Kesehatan Masyarakat Nasional 2015;9(4):353-61.

Wawan A, Dewi M. Teori dan Pengukuran Pengetahuan, Sikap, dan Perilaku Manusia. Yogyakarta: Nuha Medika; 2010

Wijaya I Made Kusuma, Mestri Ni Nyoman, Trisna Gede Doddy. Pengetahuan, Sikap, dan Aktivitas Remaja SMA dalam Kesehatan Reproduksi di Kecamatan Buleleng. Jurnal Kesehatan Masyarakat. 2014;10:33-42.

Tumbelaka Patricia, Limato Ralacia, Nasir Sudirman, Syafruddin Din, Ormel Hermen, Ahmed Rukhsana. Analisys of Indonesia's Community Health Volunteers (kader) as Maternal Health Promoters in the Community Integrated Health Service (Posyandu) Following Health Promotion Training. International Journal of Community Medicine and Public Health. 2018;5(3):856-63. 